\title{
Letters
}

\section{On autonomy and identity}

SIR

Two recent articles in this journal ${ }^{1-2}$ addressed the issue of autonomy. Both provided very interesting arguments.

Here, I address the connections between Spriggs's ${ }^{1}$ approach to autonomy in disruptive conditions and Turner's ${ }^{2}$ approach to social regulation of individual autonomy, introducing the connection between identity and autonomy in this context. Individual recognition of self-identity relates to the continuity of the self. This is essentially a connection between past and present, but the assumption of past-present continuity allows projection into the future. This projection merely states an expectation that future events will allow interpretation in such a way as not to endanger selfidentity, that is, allowing for the past-present continuity in the future.

Autonomy is the capacity for decision regarding one's relation with the external world. Its major role is the preservation of the past-present continuity, allowing recognition of selfidentity through the recognition of a coherent (meaning: continuous-like) way of conducting one's life - a sort of mastery over one's destiny.

Sudden turning points will happen from time to time, and some reinterpretation of self-identity will be needed to cope with such sudden changes (the process of growing). This reinterpretation is done regularly for minor turning points, but exceptionally important events will take a more ritualised process of self-reinterpretation - we call it grieving.

During this process of readjustment, there is a fragilisation of selfidentity, and consequentially, of autonomy. As this process is more or less time-consuming, the lack of autonomy could be more or less prolonged. Such duration will be dependent on the intensity of the provoking event and on the space allowed for the unex- pected in the person's attitude to life. Nevertheless, autonomy is essential to deal with the unexpected in such a way that identity is still self-recognisable.

In Spriggs's' presentation, it is the survivors' (those able to cope) accounts we hear. Through them, we also hear the others, those who had lost their self-identity, and their autonomy with it - the available time was not enough for their grieving. The present did not fit in with their perception of self-identity, and they were simply pushed by events without deciding or even acknowledging what was happening - humans without a present.

We have to recognise that there is wide variation in the time required to regain individual autonomy, and that this will be reflected in an individual's capacity for decision making. Some individuals will take whatever comes to them and make the most of it, keeping control of their identity and autonomy. Others are extremely dependent on external stability, and will take more time to regain their autonomous decision-making capacity. Society is a self-preserving entity, and does not rely on chance for survival. This unreliability of individuals to retain their decision-making capabilities, and this capability to re-interpret selfidentity (creating a "new" member in place of the old) was recognised by societies (ie organised communities: family, profession, nation, etc); the development of those societies, tending to adopt those rules which would stabilise the community, created mechanisms to regulate the exercise of individual autonomy. These mechanisms consist in the partial surrender of individual autonomy to society, so the individual accepts society's decisions regarding private life. Those societies presented by Turner ${ }^{2}$ as more intrusive in the individual's private affairs, can be recognised as those where marriage rules, family traditions in professional areas, and other "intrusive" rulings, persist for longer - the "patriarchal" or "matriarchal" societies. The goal is to preserve individual identity, not as self-recognised, but asĩ socially recognised. As this surrender is cultural and, as such, "built-in" as: opposed to "coercive", it may be said $\overrightarrow{\vec{A}}$ that such surrender of individual autonomy is an autonomous act.

What I would like to stress is the need to support autonomy, if selfidentity is to be recovered in such cri- $\mathbb{D}$ ses, and the need, also, to allow for theథ diversity of humanity, resisting the 3 normative tendencies of society.

\section{References}

1 Spriggs $M$. Autonomy in the face o devastating diagnosis. fournal of Medi cal Ethics 1998;24:123-6.

2 Turner L. An anthropological exploration of contemporary bioethics: the응 varieties of common sense. fournal of Medical Ethics 1998;24:127-33.

\section{Disclaimer}

The opinions stated are those of the author alone, his responsibility. They do not reflect the views or the practice? of the Emergency Department or the $\frac{}{3}$ North Staffs Hospital NHS Trust.

J CALINAS-CORREIA Critical Care Fellow, Accident and Emergency Department, North Staffs Hospital, , Stoke-on-Trent

\section{The ethics of xenotransplantation}

SIR

Jonathan Hughes's thorough examination of the ethical issues raised by xenotransplantation concludes that itc is necessary to put a moratorium in place $^{1}$ and hence goes further than two recent $\mathrm{UK}$ reports on the subject. ${ }^{2-3} \overline{\mathrm{T}}$ $\mathrm{He}$ argues that the moratorium should? stand at least until possible avenues foro increasing the supply of human organs have been exhausted and until a more reassuring judgment can be reached on the prospects for preventing and 
containing transmitted infections. This letter examines each of these requirements in turn.

\section{Possible avenues for increasing the supply of human organs}

Hughes suggests two possibilities, both controversial, for increasing the supply of human organs. The first is the use of opting-out systems of organ donation. Advocates argue that such systems have been successful in increasing the supply of human organs, yet it is not easy to be sure that any increase in organ donation is not due to other factors, for example, simultaneous improvements in transplant coordination. Even were opting out to be adopted in the UK, the increase in organ donation would be limited. Of the 13,000 expected deaths each year in intensive care units only $10 \%$ will have a confirmed diagnosis of brain stem death. Of these 1300 people, a further $10 \%$ will not be suitable donors for medical reasons. Twothirds of those remaining already become organ donors: an-opting out policy would increase organ donation only by the 400 or so people whose families currently refuse consent to organ donation. ${ }^{4}$ In contrast, about 4,500 people remain on the waiting list for kidneys alone.

The even more controversial proposal to allow the removal of organs from anencephalic infants and patients in persistent vegetative state would need thorough consideration and debate. Even if, after such debate, such a practice was considered to be ethically and socially acceptable, using organs from the small numbers of anencephalic babies and patients in persistent vegetative state would not solve the organ shortage.

The Nuffield Council's report reviewed, not only possibilities for increasing the supply of human organs, but also the potential for reducing the demand for transplants by promoting public health, reducing disease and developing artificial organs and tissue.
The report concluded that, while all these approaches are important and should be encouraged, they cannot eliminate or meet the demand for transplantation. Thus xenotransplantation merits consideration as one of a range of options for helping to meet this demand.

\section{Prospects for preventing and con- taining transmitted infections}

Hughes is concerned that the two UK reports on xenotransplantation were insufficiently cautious in the light of the risk of transmitting infectious disease to the wider population and questions whether the safeguards proposed go far enough. The Nuffield Council's report recommended that a committee with the expertise to assess the possible risks of disease transmission be established and that any clinical trials on xenotransplantation should depend on approval by that committee. The Department of Health report made similar recommendations and the government responded by establishing the UK Xenotransplantation Interim Regulatory Authority (UKXIRA) in $1997 .^{\circ}$

While Hughes is right that "full knowledge of potentially [infectious] agents is for all practical purposes impossible" ${ }^{\text {" this }}$ argument has been used by some to advocate a rapid move to clinical trials (since it will never be possible to eliminate all the risks) as well as, by others, extreme caution. Both positions neglect the fact that there is much research that can, should and is being done. A sobering example is the newly emerging evidence that pigs harbour endogenous porcine retroviruses which it will be difficult, if not impossible, to eliminate by breeding. ${ }^{8}$ With the establishment of the UKXIRA, the regulatory machinery is now in place, in this country at least, to examine and address such evidence.

In considering the risks of disease transmission alone it is almost impossible not to be pessimistic but these risks are only part of the wider context in which xenotransplantation must be considered. As the findings about endogenous retroviruses show, further research will not necessarily be reassuring and a demand for complete certainty is not realistic. But since any innovation must, by definition, carry some unknowable risks it would be unacceptably conservative to restrict innovation merely by appeal to the possibility of risk. As pointed out in a report by the US Institute of Medicine, "our own humanity is diminished if, in order to protect ourselves, we turn away from others whose suffering is both clearly visible to us and more clearly devastating in its impact on them".

\section{References}

1 Hughes J. Xenografting: ethical issues. fournal of Medical Ethics 1998; 24:1824.

2 Nuffield Council on Bioethics. Animalto-human transplants: the ethics of xenotransplantation. London:Nuffield Council on Bioethics, 1996.

3 Advisory Group on the Ethics of Xenotransplantation. Animal tissue into humans: a report by the Advisory Group on the Ethics of Xenotransplantation. London: Stationery Office, 1997.

4 Gore SM, Cable DJ and Holland AJ. Organ donation from intensive care units in England and Wales: two year confidential audit of deaths in intensive care. British Medical fournal 1991; 304 349-55.

5 UK Transplant Support Service Authority figure for 31 March 1998.

6 Department of Health. Report on animal to human transplants published, consultation exercise launched. Press release 97/010, 16 January 1997 (available via http://www.open.gov.uk)

7 See reference 1: 21

8 Le Tissier P, Stoye JP, Takeuchi Y, Patience $C$ and Weiss RA. Two sets of human-tropic pig retrovirus. Nature 1997; 389: 681-2.

9 Institute of Medicine. Xenotransplantation: science, ethics and public policy. Washington DC: National Academy Press, 1996.

RACHEL BARTLETT

Formerly Deputy Director, Nuffield Council on Bioethics, 28 Bedford Square, London WC1B $3 E G$ 